\title{
Mejora y adaptación virtual de Organización y Gestión Educativa
}

\author{
Virtual adaptation and \\ improvement of Educational \\ Organization and Management
}

Antonio Palacios-Rodríguez

https://orcid.org/0000-0002-0689-6317

Universidad de Sevilla

Didáctica y Organización Educativa

aprodriguez@us.es

DOI: http://dx.doi.org/10.12795/9788447231003.080

Pp.: 1714-1735 


\section{Descripción del contexto}

Con la aplicación de un Ciclo de Mejora en el Aula (CIMA) anterior, pude reflexionar sobre los beneficios del trabajo grupal. Además, aprendí sobre la importancia de incorporar preguntas inspiradoras o conflictos cognitivos en los que se hace dudar al alumnado: éste debe expresar sus ideas libremente, siempre con una guía de la actividad, supervisión personalizada del docente y posterior entrega de un informe que deje constancia del aprendizaje desarrollado (Palacios-Rodríguez, 2020).

Este CIMA es planteado dentro de la asignatura "Organización y Gestión Educativa" del Grado en Pedagogía de la Universidad de Sevilla. Esta asignatura, de 8 créditos, es impartida durante el 1er cuatrimestre del 2o año y tiene carácter obligatorio. Además, es compartida con otra docente que, de forma recurrente, imparte la asignatura. Existen un total de 3 grupos (uno será objeto de este CIMA) y el nivel de coordinación entre los docentes es excelente, lo que ha facilitado el desarrollo del ciclo de mejora.

En relación al alumnado, se cuenta con 40 estudiantes matriculados: 35 alumnas y 5 alumnos. La media de edad es 22 años. La mayoría provienen de Sevilla capital (11) y pueblos de la provincia (12). La mayoría afirma que la elección del Grado era su primera opción (80,2\%). De acuerdo con los datos recopilados en el cuestionario inicial, ningún estudiante manifiesta tener alguna necesidad específica de aprendizaje.

El Ciclo de Mejora pretende tener en cuenta las demandas directas del alumnado, canalizadas a través de un cuestionario inicial elaborado con Google Forms denominado "datos de contacto y otras cuestiones" en el que se plantea, entre otras cuestiones, “¿qué esperas de la asignatura (aparte de aprobar)?", “si fueras el docente, ¿qué nuevos métodos de enseñanza emplearías?" o "¿cómo puedo

Ciclos de Mejora en el Aula (2020). Experiencias de Innovación Docente de la US Esta obra se distribuye con la licencia Creative Commons 
ayudarte este curso?". Se puede acceder al cuestionario a partir del siguiente enlace: https://bit.ly/3ofwuWJ. En la Tabla 1 se recogen alguna de las respuestas obtenidas. Al ser uno de los puntos recogidos en el cuestionario, en todo momento se ha contado con el consentimiento del alumnado para publicar sus respuestas anonimizadas en este trabajo.

Tabla 1. Algunas de las respuestas obtenidas por el alumnado en el cuestionario "datos de contacto y otras cuestiones"

\begin{tabular}{|c|c|c|}
\hline $\begin{array}{l}\text { ¿Qué esperas de esta } \\
\text { asignatura? (aparte de } \\
\text { aprobar). }\end{array}$ & $\begin{array}{l}\text { Si fueras el docente, } \\
\text { ¿qué nuevos métodos } \\
\text { de enseñanza } \\
\text { emplearias? }\end{array}$ & $\begin{array}{l}\text { ¿Cómo puedo ayudarte } \\
\text { este curso? }\end{array}$ \\
\hline $\begin{array}{l}\text { Según su nombre, } \\
\text { puedo entender que } \\
\text { a lo largo del curso } \\
\text { estudiaremos las } \\
\text { formas de organizar, } \\
\text { evaluar, gestionar los } \\
\text { centros de enseñanza. } \\
\text { Debe de funcionar } \\
\text { desde dentro para que } \\
\text { se obtengan resultados. } \\
\text { El planificar y gestionar } \\
\text { lo relacionado con } \\
\text { las instituciones } \\
\text { educativas no es algo } \\
\text { que se pueda hacer a la } \\
\text { ligera. Creo que es algo } \\
\text { bastante importante, } \\
\text { me despierta } \\
\text { cierta curiosidad la } \\
\text { asignatura. Pienso que } \\
\text { aprenderé muchas } \\
\text { cosas. }\end{array}$ & $\begin{array}{l}\text { Un método donde el } \\
\text { alumnado sea activo } \\
\text { y participativo, para } \\
\text { que el aprendizaje } \\
\text { sea más autónomo (el } \\
\text { docente se encargaría } \\
\text { de resolver las dudas) y } \\
\text { darle más importancia } \\
\text { al trabajo que elabora y } \\
\text { al progreso que tenga, } \\
\text { es decir, su evolución } \\
\text { a lo largo del curso, } \\
\text { es decir, el docente } \\
\text { tomaría un papel } \\
\text { secundario. Por lo } \\
\text { que realizaría trabajos } \\
\text { tanto grupales como } \\
\text { individuales e incluso } \\
\text { no realizaría exámenes } \\
\text { si la asignatura cursada } \\
\text { no lo requiere. }\end{array}$ & $\begin{array}{l}\text { La ansiedad y el estrés } \\
\text { son cosas que todavía } \\
\text { estoy aprendiendo a } \\
\text { gestionar y me ayuda } \\
\text { poder tener la tarea } \\
\text { que tengo que realizar } \\
\text { bien detallada para } \\
\text { estar segura de estar } \\
\text { haciéndolo de la forma } \\
\text { en la que se pide hacer } \\
\text { el trabajo. Es decir, } \\
\text { tener una explicación } \\
\text { clara sobre las tareas } \\
\text { a realizar. También me } \\
\text { ayuda que el profesor } \\
\text { no adopte un rol } \\
\text { estricto sino amigable, } \\
\text { de acompañamiento } \\
\text { y de motivación por } \\
\text { aprender. }\end{array}$ \\
\hline
\end{tabular}

Ciclos de Mejora en el Aula (2020). Experiencias de Innovación Docente de la US Esta obra se distribuye con la licencia Creative Commons Reconocimiento-NoComercial-SinObraDerivada Internacional (CC BY-NC-ND 4.0.) 
Tomar contacto por primera vez en el grado con una asignatura que tiene relación directa con nuestro futuro desarrollo profesional (ya que las asignaturas de primero se basaban más en las bases teóricas del grado).
Ante la situación que nos ha tocado este curso, sinceramente no sabría cómo mejorarlo. En condiciones normales no suelo ser nada partidaria de las clases magistrales, me gusta mucho el uso de videos explicativos de forma que si alguien no lo ha entendido pueda repetirlo las veces que les sean necesarias, al igual que el uso de los documentos base o temas para que nuestro aprendizaje sea más ordenado.

Seguramente un método en el que se convine una explicación por parte del docente y otra parte en la que el alumnado utilice su razonamiento. Por ejemplo una vez explicada la teoría, el profesor plantea un problema y los alumnos deben pensar cómo se identifica y se soluciona teniendo como referencia la explicación del profesor.
Una buena

organización desde el principio de curso me ayudaría mucho ya que de esa manera lo llevo todo al día y así evito dejarlo todo para final y no agobiarme
Soy una persona que me cuesta participar en clase de manera individual, por ello me ayuda mucho el trabajar en pequeños grupos. 


\begin{tabular}{|l|l|l|}
\hline $\begin{array}{l}\text { Simplemente aprender } \\
\text { todo lo que necesito } \\
\text { saber para en un } \\
\text { futuro desempeñar } \\
\text { esta profesión lo mejor } \\
\text { posible. }\end{array}$ & $\begin{array}{l}\text { Aplicaría métodos } \\
\text { más innovadores, } \\
\text { dejando a un lado } \\
\text { algunos métodos tan } \\
\text { tradicionales. Por } \\
\text { ejemplo, considero que } \\
\text { la participación del } \\
\text { alumnado debe estar } \\
\text { muy presente a la hora } \\
\text { de dar clases, para } \\
\text { que así no se realicen } \\
\text { participativas (a pesar } \\
\text { de las restricciones } \\
\text { impuestas a causa del } \\
\text { CovID) }\end{array}$ \\
\hline $\begin{array}{l}\text { clases monótonas... } \\
\text { Poder conocer más } \\
\text { sobre el sistema }\end{array}$ & $\begin{array}{l}\text { Emplearía un método } \\
\text { más enfocado a } \\
\text { la práctica. Casos } \\
\text { prácticos reales, } \\
\text { debates, ronda de } \\
\text { preguntas y respuestas, } \\
\text { etc. }\end{array}$ & $\begin{array}{l}\text { Que las clases sean } \\
\text { llevaderas y no como } \\
\text { algunos docentes que } \\
\text { se centran en leer los } \\
\text { temas }\end{array}$ \\
\hline
\end{tabular}

Como se puede observar, la mayoría hace referencia a la practicidad del conocimiento y uso de recursos y metodologías activas para el desarrollo de competencias clave. Además, también se menciona el aprendizaje significativo, flexible y centrado en el alumnado. Por este motivo, el ciclo de mejora se centra en el desarrollo de una investigación sobre la incidencia de la legislación educativa en las instituciones de formación.

\section{Diseño previo del CIMA}

\section{Objetivos}

El principal objetivo de este ciclo de mejora es aumentar el nivel competencial del alumnado a través de 8 sesiones en las que se favorece el aprendizaje basado en la investigación. Concretamente, se pretende:

Ciclos de Mejora en el Aula (2020). Experiencias de Innovación Docente de la US Esta obra se distribuye con la licencia Creative Commons 
1. Complejizar las concepciones sobre la incidencia de la legislación en la organización y planificación escolar.

a) Analizar en qué medida la legislación escolar incide en la organización de los centros educativos.

b) Comprender y analizar la evolución en la organización de los centros a través de las leyes de educación promulgadas en España.

c) Conocer el contenido de la legislación vigente en lo que se refiere a la organización y planificación de los centros educativos.

2. Aumentar el nivel de compromiso, implicación, participación y satisfacción del alumnado.

3. Conocer y usar recursos digitales integrables en los procesos de E-A para: información y alfabetización digital, comunicación y colaboración, creación de contenido digital, seguridad y resolución de problemas.

\section{Ideas iniciales del alumnado}

Analizar los procesos de cambio y los obstáculos que dificultan la progresión en el aprendizaje es una tarea fundamental en una evaluación formativa y para el aprendizaje del alumnado (Rivero y Porlán, 2017). Por este motivo, para explorar las ideas del alumnado (sus modelos mentales), se parte de un cuestionario inicial anónimo de preguntas abiertas. Este cuestionario pretende ser una herramienta capaz de aportar información relevante para adaptar el proceso de enseñanza-aprendizaje. Dicho cuestionario es cumplimentado en la primera sesión y su duración es de aproximadamente 15 minutos. En él, se plantearán 2 situaciones abiertas (una por cada contenido) relacionadas con problemas atractivos y relevantes:

Ciclos de Mejora en el Aula (2020). Experiencias de Innovación Docente de la US Esta obra se distribuye con la licencia Creative Commons 
a) ¿En qué medida crees que las leyes educativas afectan a la organización de los centros educativos? (ORGANIZACIÓN)

b) ¿Cuál crees que ha sido la evolución de las leyes de educación promulgadas en España?, ¿Qué sabes sobre la LOMCE? (EVOLUCIÓN)

Se utiliza la herramienta Google Forms por ser capaz de generar cuestionarios de este tipo, dando la posibilidad de descargar las respuestas en forma de matriz de datos (facilidad de análisis). Por cada pregunta, se realiza una clasificación de "respuestas tipo" en forma de "escalera de aprendizaje", atendiendo a su nivel de complejidad. En la Tabla 2 se representan los núcleos conceptuales del tema (preguntas), así como los niveles detectados, el porcentaje de alumnado en cada uno y respuestas tipo. Conjuntamente, estas respuestas sirven como objeto de reflexión en la última actividad propuesta.

Tabla 2. Núcleos conceptuales (preguntas), niveles, porcentaje y ejemplos

\begin{tabular}{|c|l|c|l|}
\hline Núcleo & Nivel (escalera) & \% & \multicolumn{1}{c|}{ Ejemplo } \\
\hline ORGANIZACIÓN & $\begin{array}{l}\text { La legislación } \\
\text { educativa afecta a } \\
\text { la organización de } \\
\text { las instituciones } \\
\text { de formación } \\
\text { (nivel inicial) }\end{array}$ & $77,3 \%$ & $\begin{array}{l}\text { Teniendo en cuenta } \\
\text { que un centro se rige } \\
\text { por la leyes que están } \\
\text { establecidas por el } \\
\text { gobierno, la organización } \\
\text { de este centro debe } \\
\text { estar acorde en todos los } \\
\text { sentidos a las medidas } \\
\text { que exigen estas leyes. }\end{array}$ \\
\hline
\end{tabular}

Ciclos de Mejora en el Aula (2020). Experiencias de Innovación Docente de la US Esta obra se distribuye con la licencia Creative Commons 


\begin{tabular}{|c|c|c|c|}
\hline \multirow[t]{2}{*}{ ORGANIZACIÓN } & $\begin{array}{l}\text { La legislación, } \\
\text { condicionada } \\
\text { por factores } \\
\text { educativos, } \\
\text { políticos, sociales, } \\
\text { económicos... } \\
\text { afecta a la } \\
\text { organización de } \\
\text { las instituciones } \\
\text { de formación } \\
\text { (nivel intermedio) }\end{array}$ & $13,6 \%$ & $\begin{array}{l}\text { A pesar de que se intenta } \\
\text { que sean igualitarias, no } \\
\text { todos los centros tienen } \\
\text { los mismos recursos, por } \\
\text { ello afectan de manera } \\
\text { totalmente diferente. } \\
\text { Mientras que a a algunos } \\
\text { una ley les puede } \\
\text { favorecer en mayor } \\
\text { medida a otros los puede } \\
\text { hacer en menor medida } \\
\text { e incluso desfavorecerles } \\
\text { aunque creo que todas se } \\
\text { hacen con el propósito de } \\
\text { favorecer. }\end{array}$ \\
\hline & $\begin{array}{l}\text { La legislación } \\
\text { educativa } \\
\text { española, } \\
\text { condicionada } \\
\text { por factores } \\
\text { educativos, } \\
\text { políticos, sociales, } \\
\text { económicos... } \\
\text { afecta a la } \\
\text { organización de } \\
\text { las instituciones } \\
\text { de formación. } \\
\text { Además, existen } \\
\text { distintos niveles } \\
\text { de aplicación y } \\
\text { concreción de } \\
\text { acuerdo con las } \\
\text { competencias } \\
\text { Estado- } \\
\text { Autonomías (nivel } \\
\text { avanzado) }\end{array}$ & $9 \%$ & $\begin{array}{l}\text { Creo que las leyes } \\
\text { educativas afectan } \\
\text { bastante puesto que } \\
\text { el Gobierno y las } \\
\text { Comunidades Autónomas } \\
\text { son los que dictan como } \\
\text { ha de estructurarse } \\
\text { cada centro educativo. } \\
\text { Pero también afecta la } \\
\text { financiación del centro y } \\
\text { otros asuntos. }\end{array}$ \\
\hline
\end{tabular}

Ciclos de Mejora en el Aula (2020). Experiencias de Innovación Docente de la US Esta obra se distribuye con la licencia Creative Commons 


\begin{tabular}{|c|c|c|c|}
\hline \multirow[t]{3}{*}{ EVOLUCIÓN } & $\begin{array}{l}\text { Legislación } \\
\text { educativa actual } \\
\text { (nivel inicial) }\end{array}$ & $71,3 \%$ & $\begin{array}{l}\text { Que es una reforma } \\
\text { educativa, ley orgánica } \\
\text { que pretende mejorar la } \\
\text { educación cambiando } \\
\text { algunos artículos de la } \\
\text { ley orgánica anterior. }\end{array}$ \\
\hline & $\begin{array}{l}\text { Legislación } \\
\text { educativa } \\
\text { actual, historia, } \\
\text { tramitación, } \\
\text { medidas (nivel } \\
\text { intermedio) }\end{array}$ & $16 \%$ & $\begin{array}{l}\text { Que es la ley educativa } \\
\text { vigente en España } \\
\text { a día de hoy. Fue } \\
\text { sustituda por la LOE. } \\
\text { Es la ley orgánica para } \\
\text { la mejora de la calidad } \\
\text { educativa y uno de sus } \\
\text { principales objeticos es } \\
\text { que la educación sea el } \\
\text { motor que promueva el } \\
\text { bienestar de nuestro país. }\end{array}$ \\
\hline & $\begin{array}{l}\text { Legislación } \\
\text { educativa } \\
\text { actual, historia, } \\
\text { tramitación, } \\
\text { medidas, crítica, } \\
\text { incidencia en el } \\
\text { Sistema Educativo } \\
\text { (nivel avanzado) }\end{array}$ & $12,6 \%$ & $\begin{array}{l}\text { La LOMCE es la ley } \\
\text { orgánica para la mejora } \\
\text { de la calidad educativa. } \\
\text { Su principal objetivo diría } \\
\text { que entre otros muchos } \\
\text { es mejorar la atención } \\
\text { a la diversidad. Desea } \\
\text { cambiar y mejorar la } \\
\text { educación, además de } \\
\text { implementar la inclusión } \\
\text { de todos los alumnos / } \\
\text { as en el aula. Es la que } \\
\text { actualmente está en } \\
\text { vigor. Anteriormente } \\
\text { estaba en vigor la } \\
\text { LOE (ley orgánica de } \\
\text { educación). }\end{array}$ \\
\hline
\end{tabular}

En todos los casos, la mayoría de los alumnos y alumnas se sitúan en el primer nivel o escalón. En consecuencia, se diseña una secuencia de actividades para ayudar a superar los obstáculos detectados y ayudarles a avanzar hacia los siguientes niveles.

Ciclos de Mejora en el Aula (2020). Experiencias de Innovación Docente de la US Esta obra se distribuye con la licencia Creative Commons 


\section{Contenidos}

El docente debe cuestionarse qué y cómo va a trabajar con el alumnado. En relación al qué trabajar, hasta el momento se ha desarrollado este tema de forma eminentemente magistral, describiendo las principales características de la legislación educativa vigente.

Una vez analizados los datos del cuestionario inicial, se realiza un nuevo mapa de contenidos basado en los problemas planteados del cuestionario inicial, así como relación y clasificación en contenidos conceptuales, procedimentales y actitudinales (Figura 1).

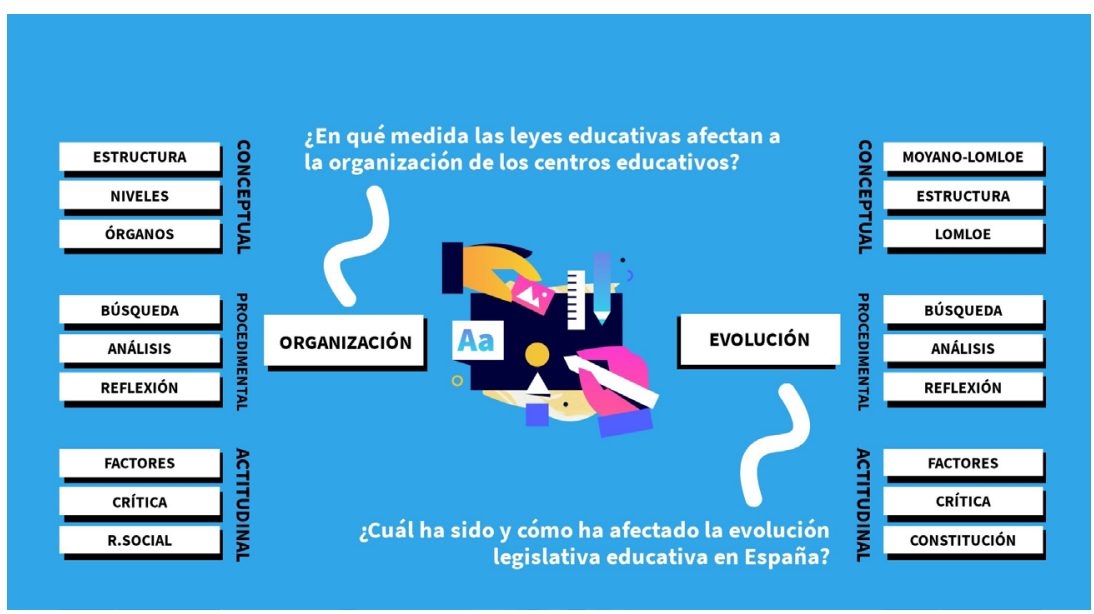

Figura 1. Mapa de contenidos

Desarrollando el mapa de contenidos, los contenidos específicos a trabajar en este ciclo de mejora docente son:

1. Contenido conceptual:

a) Comprender la evolución en la organización de los centros a través de las leyes de educación promulgadas en España.

i) Estructura del Sistema Educativo.

ii) Niveles del Sistema Educativo.

iii) Órganos colegiados. Ciclos de Mejora en el Aula (2020). Experiencias de Innovación Docente de la US
Esta obra se distribuye con la licencia Creative Commons Reconocimiento-NoComercial-SinObraDerivada $\quad 4.0$ Internacional (CC BY-NC-ND 4.0.) 
b) Conocer el contenido de la legislación vigente en lo que se refiere a la organización y planificación de los centros educativos.

i) Evolución legislativa: Ley Moyano-LOMLOE.

2. Contenido procedimental:

a) Analizar en qué medida la legislación escolar incide en la organización de los centros educativos.

i) Búsqueda de documentos en los que se ponga de manifiesto la incidencia legislativa.

ii) Análisis de documentos.

iii) Reflexión sobre la incidencia legislativa a lo largo de la historia de España.

b) Analizar la evolución en la organización de los centros a través de las leyes de educación promulgadas en España.

i) Búsqueda de documentos en los que se analiza la evolución de las organizaciones educativas a lo largo de la historia.

ii) Análisis de documentos.

iii) Reflexión sobre la evolución de las organizaciones educativas de acuerdo con la legislación.

3. Contenido actitudinal:

a) Valoración de los factores determinantes en términos legislativos (organización y evolución): sociales, políticos, económicos, educativos...

b) Crítica sobre la inestabilidad legislativa y su repercusión en la organización de las instituciones educativas

c) Valoración de la realidad social que ha afectado a la evolución legislativa.

d) Factores

e) Tolerancia y respeto por los valores constitucionales relativos al Derecho a la Educación. 


\section{Metodología}

La metodología planteada persigue complejizar las ideas del alumnado respecto a la realidad educativa española. Todo ello, a través de diferentes situaciones que suponen un desafío cognitivo para el mismo. Desde la primera sesión se organizarán pequeños grupos, pues suponen: participación del alumnado, aprendizaje cooperativo, interacción y motivación (Finkel, 2008). Al mismo tiempo, el papel del docente será el de supervisar el trabajo de los grupos y solucionar los problemas funcionales y cognitivos que se plantean en cada uno de ellos. En todo momento se intentará conseguir la atención y curiosidad del alumnado, tratando de partir de sus ideas y desarrollando competencias de aprendizaje autónomo mediante propuestas estimulantes y significativas (Bain, 2005).

Conjuntamente, se proporciona un espacio para la presentación de resultados finales (producto final). De esta forma, la experiencia está completa al tener un inicio o presentación del problema, medio o resolución del problema y fin o presentación de resultados. Así, el modelo metodológico que se plantea para todas las sesiones (Figura 4) está basado en:

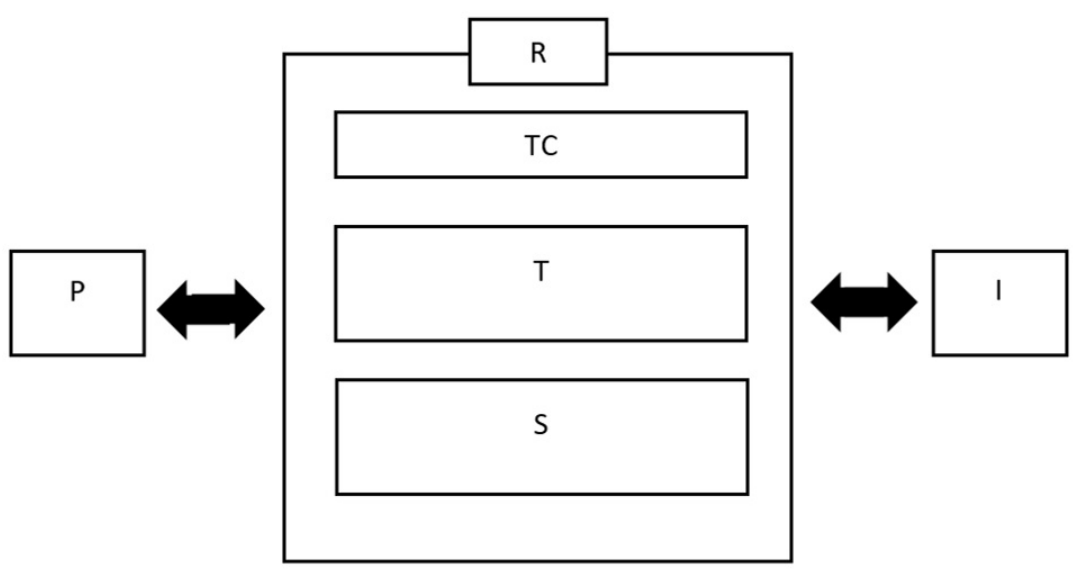

Figura 2. Modelo metodológico

Ciclos de Mejora en el Aula (2020). Experiencias de Innovación Docente de la US Esta obra se distribuye con la licencia Creative Commons 
1. R: Resolución de problemas

a) ¿En qué medida crees que la legislación escolar (leyes educativas) condicionan la organización de los centros educativos?

b) ¿Cuál crees que ha sido la evolución en la organización de los centros a través de las leyes de educación promulgadas en España?

c) ¿Qué contenido piensas que se contempla en la ley educativa vigente en lo que se refiere a la organización y planificación de los centros educativos?

2. TC: Trabajo cooperativo

a) Trabajo grupal

b) Reflexión individual

c) Coevaluación del alumnado

3. T: Uso de las TIC

a) Uso de la plataforma educativa como medio para investigar, realizar las secuencias de actividades, trabajo cooperativo, resolución de dudas, debate...

b) Búsqueda de información en fuentes fiables.

c) Investigación sobre temática elegida por el alumnado, a partir de sus intereses.

d) Exposición apoyada en material multimedia (creación de contenido digital).

4. S: Sintesis final

a) Exposición oral

b) Entrega de informe

En todas las fases, el papel del profesor $(P)$ es el de orientar el trabajo grupal. Éste aporta retroalimentación durante la realización de la tarea, en la entrega del borrador y en la entrega del informe final. Conjuntamente, todo el proceso debe ir ajustándose a las ideas del alumnado 
(I); el tema no se impone, el alumnado lo propone. Por este motivo, cada grupo trabaja sobre una problemática relevante para el mismo.

El rechazo del poder tradicional del profesor, otorgando mayor protagonismo a las alumnas y alumnos, hace que las clases se conviertan en un espacio para explorar y encontrar; dudar, debatir y reflexionar; errar y mejorar. Aquel donde experimentan y aprenden personas distintas.

Ciclos de Mejora en el Aula (2020). Experiencias de Innovación Docente de la US Esta obra se distribuye con la licencia Creative Commons 


\section{Actividades}

\section{A continuación, se describe la secuencia de actividades} propuesta (Tabla 2).

\section{Tabla 2. Secuencia de actividades}

\begin{tabular}{|c|c|c|c|c|}
\hline Sesión & Actividad & Pregunta asociada (objetivo) & Descripción & Duración \\
\hline \multirow[t]{2}{*}{1} & $\begin{array}{l}\text { A1. Creación } \\
\text { del grupo }\end{array}$ & $\begin{array}{l}\text { Conocer y usar recursos } \\
\text { digitales integrables en } \\
\text { los procesos de E-A para: } \\
\text { información y alfabetización } \\
\text { digital, comunicación y } \\
\text { colaboración, creación de } \\
\text { contenido digital, seguridad y } \\
\text { resolución de problemas. Este } \\
\text { objetivo se trabajará en todas } \\
\text { las actividades de forma } \\
\text { transversal. }\end{array}$ & $\begin{array}{l}\text {-Realización del cuestionario } \\
\text { de ideas previas. } \\
\text {-Presentación del alumnado } \\
\text { (soy..., puedo aportar...). } \\
\text { Dinámica presencial. } \\
\text {-Creación del grupo (max. } 3 \\
\text { personas). } \\
\text {-Nombre del grupo } \\
\text { (consenso). } \\
\text {-Designación de roles: } \\
\text { portavoz, coordinador, } \\
\text { investigador de recursos, } \\
\text { cohesionador... } \\
\text {-Uso del BlackBoard creado } \\
\text { por el docente }\end{array}$ & 1 hora \\
\hline & $\begin{array}{l}\text { A2. Lectura y } \\
\text { búsqueda de } \\
\text { noticia }\end{array}$ & $\begin{array}{l}\text { Analizar en qué medida la } \\
\text { legislación escolar incide en } \\
\text { la organización de los centros } \\
\text { educativos. }\end{array}$ & $\begin{array}{l}\text { Lectura: "Incidencia de la } \\
\text { legislación en la organización } \\
\text { y planificación escolar" } \\
\text { Buscar, como mínimo, una } \\
\text { noticia (video o texto), } \\
\text { entrada en blog o debate } \\
\text { en foro en el que se discuta } \\
\text { sobre la legislación educativa. } \\
\text { Adjuntar un archivo PDF } \\
\text { que contenga la siguiente } \\
\text { información: } \\
\text { - URL donde se encuentra la } \\
\text { notica } \\
\text { - Principales ideas } \\
\text { - ¿Crees que el contenido } \\
\text { está sesgado?, ¿por qué? } \\
\text { - Relación entre las } \\
\text { principales ideas y la realidad } \\
\text { educativa }\end{array}$ & 1 hora \\
\hline
\end{tabular}

Ciclos de Mejora en el Aula (2020). Experiencias de Innovación Docente de la US Esta obra se distribuye con la licencia Creative Commons 


\begin{tabular}{|c|c|c|c|c|}
\hline \multirow[t]{3}{*}{2} & A3. Debate & $\begin{array}{l}\text { Analizar en qué medida la } \\
\text { legislación escolar incide en } \\
\text { la organización de los centros } \\
\text { educativos. }\end{array}$ & $\begin{array}{l}\text { Debate sobre las cuestiones } \\
\text { planteadas en la sesión } \\
\text { anterior: } \\
\text {-Por grupos, presentación del } \\
\text { trabajo realizado } \\
\text {-Anotación de ideas } \\
\text { principales } \\
\text {-Similitudes/diferencias } \\
\text {-Reflexión sobre el sesgo del } \\
\text { contenido } \\
\text {-Reflexión sobre la relación } \\
\text { entre las principales ideas y } \\
\text { la realidad educativa }\end{array}$ & 1 hora \\
\hline & $\begin{array}{l}\text { A4. Resumen } \\
\text { del debate }\end{array}$ & $\begin{array}{l}\text { Analizar en qué medida la } \\
\text { legislación escolar incide en } \\
\text { la organización de los centros } \\
\text { educativos. }\end{array}$ & $\begin{array}{l}\text { Reflexionar sobre: } \\
\text { ¿Qué has aprendido? } \\
\text { ¿Cuál ha sido tu grado de } \\
\text { implicación en el debate?, } \\
\text { ¿por qué? } \\
\text { ¿Cuál ha sido la parte que } \\
\text { más te ha interesado? } \\
\text { ¿¿Sobre qué te gustaría } \\
\text { profundizar? } \\
\text {-Valoración del debate } \\
\text { (ventajas, inconvenientes, } \\
\text { cómo mejorarlo...) } \\
\text {-Entrega de esta tarea por } \\
\text { plataforma y evaluación por } \\
\text { pares (contenido y faltas de } \\
\text { ortografía) }\end{array}$ & $1 / 2$ hora \\
\hline & $\begin{array}{l}\text { A5. } \\
\text { Investigación } \\
\text { (I) }\end{array}$ & $\begin{array}{l}\text { Comprender y analizar la } \\
\text { evolución en la organización } \\
\text { de los centros a través de } \\
\text { las leyes de educación } \\
\text { promulgadas en España. } \\
\text { Conocer el contenido de la } \\
\text { legislación vigente en lo que } \\
\text { se refiere a la organización y } \\
\text { planificación de los centros } \\
\text { educativos. }\end{array}$ & $\begin{array}{l}\text { Elegir } 1 \text { ley educativa sobre la } \\
\text { que investigar. } \\
\text { RETO: Llegar a acuerdos con } \\
\text { los otros grupos para no } \\
\text { repetir trabajos: se propone } \\
\text { el uso del foro general de } \\
\text { clase }\end{array}$ & $1 / 2$ hora \\
\hline
\end{tabular}

Ciclos de Mejora en el Aula (2020). Experiencias de Innovación Docente de la US Esta obra se distribuye con la licencia Creative Commons 


\begin{tabular}{|c|c|c|c|c|}
\hline \multirow[t]{2}{*}{3} & $\begin{array}{l}\text { A6. } \\
\text { Investigación } \\
\text { (II) }\end{array}$ & $\begin{array}{l}\text { Comprender y analizar la } \\
\text { evolución en la organización } \\
\text { de los centros a través de } \\
\text { las leyes de educación } \\
\text { promulgadas en España. } \\
\text { Conocer el contenido de la } \\
\text { legislación vigente en lo que } \\
\text { se refiere a la organización y } \\
\text { planificación de los centros } \\
\text { educativos. }\end{array}$ & $\begin{array}{l}\text { Recabar información sobre: } \\
\text {-Antecedentes } \\
\text {-Origen social y político } \\
\text {-Noticias relacionadas } \\
\text {-Material relacionado } \\
\text {-Reflexión personal } \\
\text {-Testimonio de alguien que } \\
\text { haya vivido esa ley estando } \\
\text { en el Sistema Educativo } \\
\text { español } \\
\text {-Ley posterior }\end{array}$ & 3 horas \\
\hline & $\begin{array}{l}\text { A7. } \\
\text { Investigación } \\
\text { (IV) }\end{array}$ & $\begin{array}{l}\text { Comprender y analizar la } \\
\text { evolución en la organización } \\
\text { de los centros a través de } \\
\text { las leyes de educación } \\
\text { promulgadas en España. } \\
\text { Conocer el contenido de la } \\
\text { legislación vigente en lo que } \\
\text { se refiere a la organización y } \\
\text { planificación de los centros } \\
\text { educativos. }\end{array}$ & $\begin{array}{l}\text { Sintetizar en un video o } \\
\text { infografía todo el trabajo } \\
\text { realizado. } \\
\text {-Se propondrán las } \\
\text { herramientas Powtoon, } \\
\text { Genially y Canva. } \\
\text {-Entrega por plataforma del } \\
\text { material }\end{array}$ & 2 hora \\
\hline 4 & $\begin{array}{l}\text { A8. } \\
\text { Exposición de } \\
\text { resultados }\end{array}$ & $\begin{array}{l}\text { Comprender y analizar la } \\
\text { evolución en la organización } \\
\text { de los centros a través de } \\
\text { las leyes de educación } \\
\text { promulgadas en España. } \\
\text { Conocer el contenido de la } \\
\text { legislación vigente en lo que } \\
\text { se refiere a la organización y } \\
\text { planificación de los centros } \\
\text { educativos. }\end{array}$ & $\begin{array}{l}\text { Presentación del trabajo } \\
\text { realizado: } \\
\text {-Grabación de un vídeo } \\
\text { locutado } \\
\text {-Coevaluación de las } \\
\text { presentaciones a través del } \\
\text { centro de calificaciones de } \\
\text { Blackboard. }\end{array}$ & 1 horas \\
\hline
\end{tabular}

\section{Aplicación del CIMA}

En general, el nivel de satisfacción es alto; no solo del alumnado, que ha dado una retroalimentación positiva durante todas las sesiones, sino también del profesor que, a pesar de la virtualidad de la mayoría de sesiones, ha disfrutado de todas y cada una de ellas. Sin embargo, es cierto que se han producido situaciones de "estrés en línea" cuando más de un grupo solicitaba la ayuda del profesor al mismo tiempo. Conjuntamente, los tiempos

Ciclos de Mejora en el Aula (2020). Experiencias de Innovación Docente de la US Esta obra se distribuye con la licencia Creative Commons 
planificados en un primer momento no han sido los reales, teniendo que eliminar parte de algunas actividades. Por ejemplo, aunque la sesión del debate se planteó organizando a los grupos y designando portavoces, la actividad duró más de lo previsto al plantearse diferentes cuestiones controvertidas (polémica LOMLOE). Para próximas sesiones, se planteará un debate en el que: se comenta por grupos, se elige a un portavoz, se anotan las ideas clave y se debaten con el resto de portavoces en un tiempo tasado y acordado. Así mismo, se destaca la participación de todo el alumnado: salvo en contadas excepciones, todos los miembros de los grupos han colaborado en todas las tareas que se han ido proponiendo. Esto se ha podido comprobar gracias a las posibilidades de la herramienta BlackBoard Collaborate, capaz de generar informes de actividad individualizados y mostrar si el alumnado está o no usando el chat o micrófono. De la misma forma, se ha intentado resolver todos los problemas que iban surgiendo en el grupo sugiriendo usar la función "levantar mano" y designando diferentes espacios de colaboración en línea con la función "crear grupos". Finalmente, el análisis de las escaleras de aprendizaje (preCIMA y postCIMA) demuestran una evolución positiva. Se puede afirmar que se han complejizado las ideas del alumnado a través de un modelo basado en la investigación: conectando con los problemas reales del alumnado, tratando de desarrollar contenidos que van más allá de lo meramente conceptual, abordando la resolución de problemas, evaluando los modelos mentales del alumnado y negociando los ritmos de aprendizaje y evaluación.

\section{Evaluación del CIMA}

La Tabla 3 describe los instrumentos de evaluación a utilizar durante el CIMA y su ponderación sobre la totalidad de la puntuación del tema.

Ciclos de Mejora en el Aula (2020). Experiencias de Innovación Docente de la US Esta obra se distribuye con la licencia Creative Commons 
Tabla 3. Instrumentos de evaluación.

\begin{tabular}{|l|l|l|l|}
\hline \multicolumn{1}{|c|}{ Instrumento } & Quien evalúa & \multicolumn{1}{|c|}{$\begin{array}{c}\text { Cuando se } \\
\text { usa }\end{array}$} & Ponderación \\
\hline Cuestionario inicial & Profesor & $\begin{array}{l}\text { Inicio del } \\
\text { CIMA }\end{array}$ & $0 \%$ \\
\hline Cuestionario final & Profesor & $\begin{array}{l}\text { Final del } \\
\text { CIMA }\end{array}$ & $10 \%$ \\
\hline $\begin{array}{l}\text { Entrega de reflexiones } \\
\text { individuales (Blackboard) }\end{array}$ & Profesor & $\begin{array}{l}\text { Durante el } \\
\text { CIMA }\end{array}$ & $20 \%$ \\
\hline $\begin{array}{l}\text { Entrega de tareas grupales } \\
\text { (Blackboard) }\end{array}$ & Profesor & $\begin{array}{l}\text { Durante el } \\
\text { CIMA }\end{array}$ & $50 \%$ \\
\hline $\begin{array}{l}\text { Conclusiones } \\
\text { Coevaluación trabajo } \\
\text { grupal }\end{array}$ & Alumnado & $\begin{array}{l}\text { Final del } \\
\text { CIMA }\end{array}$ & $15 \%$ \\
\hline
\end{tabular}

El "aprendizaje inmediato" se valora a partir del análisis de las escaleras de aprendizaje elaboradas con los resultados del cuestionario inicial y final. Los resultados del cuestionario son mostrados en la Tabla 4.

Tabla 4. Comparación de resultados del cuestionario preCIMA y postCIMA.

\begin{tabular}{|l|l|l|c|c|}
\hline \multicolumn{3}{|c|}{ Núcleos conceptuales } & \multicolumn{3}{c|}{ Niveles de progresión } \\
\cline { 3 - 5 } & & $\mathbf{1}$ & $\mathbf{2}$ & $\mathbf{3}$ \\
\hline $\begin{array}{l}\text { Diferencia } \\
\text { (postCiMA-preCima) }\end{array}$ & Organización & $-22,3 \downarrow \downarrow$ & $-3,1 \downarrow$ & $31,9 \uparrow \uparrow$ \\
\cline { 2 - 5 } & Evolución & $-32,8 \downarrow \downarrow$ & $-2,2 \downarrow$ & $42,8 \uparrow \uparrow$ \\
\hline
\end{tabular}

Tal y como se muestra en la tabla y, tras la aplicación del CIMA, se ha producido un notable incremento de alumnado que se sitúa en los niveles más altos (2 y 3 ). Al mismo tiempo, el número de alumnos y alumnas que se situaban en el nivel más bajo (1) ha disminuido. De la misma forma, la entrega de reflexiones individuales y grupales así como la coevaluación ha demostrado que el alumnado ha sido capaz de complejizar las ideas de los estudiantes a nivel conceptual, procedimental y actitudinal.

Ciclos de Mejora en el Aula (2020). Experiencias de Innovación Docente de la US Esta obra se distribuye con la licencia Creative Commons 


\section{Evaluación del CIMA}

Aparte de todo lo comentado en apartados anteriores, hay algo que me ha llamado la atención en el desarrollo del CIMA y creo pertinente anotar. En las primeras sesiones, cuando se distribuyeron los espacios de trabajo síncronos a través de BlackBoard Collaborate, una de las alumnas comentaba que era la primera vez que abría el micrófono desde que empezó la pandemia. ¿Hasta qué punto estamos convirtiendo las sesiones virtuales en espacios aún más encorsetados que las clases magistrales presenciales?

En conclusión, la aplicación de este CIMA me ha servido para tener mayor confianza en el alumnado y en mí mismo. El rechazo del poder tradicional del profesor, otorgando mayor protagonismo a las alumnas y alumnos, hace que las clases se conviertan en un espacio para explorar y encontrar; dudar, debatir y reflexionar; errar y mejorar; aquel donde se desarrollan las competencias fundamentales para afrontar los problemas más inmediatos (y futuros) de nuestra sociedad.

De forma complementaria, este aumento de la complejización de las ideas del alumnado ha sido posible al tener en cuenta los siguientes Principios Didácticos que han guiado la experiencia presente y que mantendré en el futuro (Figura 3).

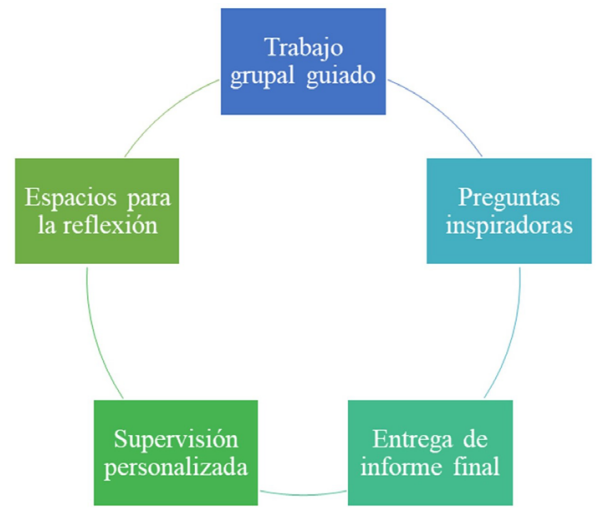

Figura 3. Principios didácticos del CIMA

Ciclos de Mejora en el Aula (2020). Experiencias de Innovación Docente de la US Esta obra se distribuye con la licencia Creative Commons 
Con la aplicación de este CIMA me ha vuelto a quedar claro que el trabajo grupal es muy beneficioso para el alumnado si se sabe dirigir adecuadamente. Conjuntamente, es esencial incorporar preguntas inspiradoras o conflictos cognitivos en los que se hace dudar al alumnado si se pretende que este vaya avanzando en los distintos niveles de progresión planteados (no se estanque). Por ello, es fundamental proporcionar espacios para la expresión libre de ideas y posterior reflexión, siempre con una guía de la actividad, supervisión personalizada del docente y entrega de un informe que deje constancia del aprendizaje desarrollado. Por este motivo y, tal y como reflexioné en el anterior CIMA, he incorporado "preguntas inspiradoras" o conflictos cognitivos a los que el alumnado no está acostumbrado; entrega de un guion de la actividad donde se deja claro qué se espera de ellos y ellas; actividades de trabajo en pequeños grupos; presencia activa del profesor en las sesiones sincronas como en los distintos espacios asíncronos (foro, correo electrónico...); dar consejos personalizados que ayuden a resolver los problemas funcionales y cognitivos del grupo (feedback a partir del centro de calificaciones y durante las sesiones síncronas); entrega de un informe final....

Ciclos de Mejora en el Aula (2020). Experiencias de Innovación Docente de la US Esta obra se distribuye con la licencia Creative Commons 
Palabras clave: Organización y Gestión Educativa, Grado en Pedagogía, Docencia Universitaria, Experimentación Docente Universitaria, Competencia Digital.

Keywords: Educational Organization and Management, University Degree in Pedagogy, University Teaching, University Teaching Experimentation, Digital Competence.

\section{Referencias bibliográficas}

Bain, K. (2005). Lo que hacen los mejores profesores universitarios. Valencia: Universitat de València.

Finkel, D. (2008). Dar clase con la boca cerrada. Valencia: Universitat de València.

Palacios-Rodríguez, A. (2020). Mejora de la Competencia Digital del futuro profesorado de Educación Secundaria: Enseñanza y Aprendizaje con TIC. En E. Navarro-Medina y R. Porlán (Coord.) Ciclos de mejora en el aula. Año 2019. Experiencias de innovación docente de la Universidad de Sevilla (pp. 2224- 2241). Sevilla: Editorial Universidad de Sevilla.

Rivero, A. y Porlán, R. (2017). La evaluación en la enseñanza universitaria. En R. Porlán (Coord.), Enseñanza Universitaria. Cómo mejorarla (pp. 73-91). Madrid: Ediciones Morata.

Ciclos de Mejora en el Aula (2020). Experiencias de Innovación Docente de la US Esta obra se distribuye con la licencia Creative Commons 